\title{
Derivation of new clinical formulae and tricolor predicting chart for estimating birth weight at term
}

\section{Okolie Vitus Ezike*, Obi Nwosu Betrand, Obiechina Nwaorah Josiah Azubuike, Okechukwu Zebulon, Egeonu Richard}

Department of Obstetrics \& Gynaecology, Nnamdi Azikiwe University Teaching Hospital, Nnewi, Southeast Nigeria

Received: 19 May 2015

Accepted: 06 June 2015

\section{*Correspondence:}

Dr. Okolie Vitus Ezike,

E-mail: vitusokolie@yahoo.com

Copyright: ( ) the author(s), publisher and licensee Medip Academy. This is an open-access article distributed under the terms of the Creative Commons Attribution Non-Commercial License, which permits unrestricted non-commercial use, distribution, and reproduction in any medium, provided the original work is properly cited.

\begin{abstract}
Background: Accurate fetal weight estimation is important for pregnancy and labor management. Clinical formulae are easy to use but have not been extensively studied. The use of the product of symphysiofundal height (SFH) and maternal abdominal girth (MAG) has been notorious for overestimating fetal weight, hence the need for its modification and production of pictorial chart for easy usage. The objective was to derive new Clinical Formulae and Tricolor birth weight predicting chart (TBPC) at term

Methods: This is a cross sectional study done in the labor ward of Nnamdi Azikiwe University Teaching Hospital, (NAUTH) Nnewi, Nigeria between 1st July, 2011 and 31 ${ }^{\text {st }}$ December, 2011. A cross section of pregnant women at term with singleton who presented in labor ward for delivery was recruited for the study. The data collected were: the gestational age, maternal weight, MAG, SFH and birth weight (BW). Analysis was with SPSS version 16.

Results: The new simple formula and the simple regression equation for predicting birth weight (BW) are $\mathrm{BW}=\mathrm{SFH}(\mathrm{MAG}-7),(\mathrm{BW})=1000+0.7 \mathrm{SFH}(\mathrm{MAG}-7)$ respectively. TBPC was constructed for estimating birth weight.

Conclusion: New formula, simple regression equation and TBPC are for birth weight estimation. The TBPC should be used in peripheral centers and referral made when necessary to a higher centre.
\end{abstract}

Keywords: Clinical formulae, Chart, Estimating, Birth weight

\section{INTRODUCTION}

Knowledge of fetal weight is important in the management of labor and delivery, especially in high risk pregnancies. For instance, the management of diabetic pregnancies, vaginal delivery after a previous caesarean section and breech presentation are influenced by the estimated fetal weight. ${ }^{1,2}$

Both low and high birth weights are associated with high risk of maternal and newborn complications during labor and puerperium. ${ }^{3,4}$ Accurate fetal weight estimation helps the care giver decide when to allow vaginal delivery, perform caesarean section or transfer a patient to a higher centre. $^{5,6}$

Although ultrasound estimation of fetal weight is reasonably sensitive, it is not readily available in many hospitals particularly in developing countries. ${ }^{7}$ This is due to paucity of ultrasound, technical know-how, and high cost of the machine as well as poor electric power supply. ${ }^{8}$ Therefore, need to develop a reliable clinical method for estimating fetal weight.

There are many clinical formulae for estimating fetal weight, but each has its limitations. To minimize these 
limitations, these formulae need review and modification from time to time. With this, a new clinical formula may be developed that will compete favorably with ultrasound in predicting fetal weight and hence the problems of estimating fetal weight will be solved in the developing countries like ours.

Clinical formulae mainly depend on SFH and most of the available data on SFH relate to Caucasian women and little information is available from measurement in African women, who are shorter; and whose angle of pelvic inclination is different resulting in nonengagement until labor is well-advanced, ${ }^{9}$ hence the need to conduct the study in our women.

The use of the product of SFH and MAG is notorious for overestimating fetal weight; hence the need for modification to reduce its overestimation of birth weight. Ojwang et al., (1980), in central Africa used the product of SFH and MAG (both in $\mathrm{cm}$ ) but MAG was measured at the highest circumference of the abdomen. ${ }^{1,10,11} \mathrm{He}$ did not consider the maternal weight or the fetal engagement. He obtained a fairly acceptable predictive value but with considerable variation from the mean. To further simplify this, Dare et al., ${ }^{10}$ at Ile- Ife in Nigeria ,used a product of SFH and MAG measured at the levels of the umbilicus (in $\mathrm{cm}$ ), and the result expressed in grams, to estimate fetal weight at term. The formula is simpler and the estimate correlated well with the actual birth weight. Dare noted overestimation of fetal weight using this formula. It is observed that the use of the product of $\mathrm{SFH}$ and MAG tends to overestimate fetal weight, ${ }^{10}$ this is important as it alerts the care giver beforehand. But this overestimation is much and hence can give a false alarm. There is need to reduce this false alarm and increase its predictability. Since maternal abdominal girth correlates less with fetal weight, than SFH does, ${ }^{7,12}$ so the MAG is the major source of error in using the formula. Therefore there is need to reduce its contribution in birth weight estimation by subtracting a factor from it. This study is set to find this correction factor, $\mathrm{BW}=\mathrm{SFH}(\mathrm{MAG}-\mathrm{X})$, where $\mathrm{X}$ is the factor. Converting this new formula into pictorial chart for easier application for the less mathematical group of health workers is important.

\section{METHODS}

A cross section of pregnant women at term with singleton who presented in labor for delivery/elective caesarean section/induction of labor was recruited. This was study done in the labor ward of NAUTH Nnewi, South East, Nigeria between 1stJuly, 2013 and 31st December, 2013, after ethical committee clearance

\section{The inclusion criteria}

- $\quad$ live term singleton pregnancy or fresh stillbirth

- Longitudinal lie

- $\quad$ Presenting part not engaged

- $\quad$ Maternal weight $\leq 95 \mathrm{~kg}$.

\section{The exclusion criteria}

- Uterine fibroid/Adnexal mass

- Polyhydramnios/oligohydramnios

- Rupture of membranes

- Antepartum hemorrhage

\section{Data collection}

Information on age, parity and gestational age were obtained. The maternal weight, SFH and MAG were measured and after delivery, the actual birth weight was obtained, and all were recorded in the proforma.

\section{Clinical measurements}

The SFH was taken with a simple metric tailors' tape made of non-elastic material, after emptying the bladder. With the patient in the supine position, heads slightly raised and the legs straight, the measurement was taken from the upper border of the pubic symphysis in the midline to the highest point of the uterine fundus, after the fundus had been defined by light palpation exerted in a plane at right angle to the abdominal wall. The measurement recorded in $\mathrm{cm}$ to the nearest $0.5 \mathrm{~cm}$.

The MAG was taken with the same tape at the level of the umbilicus at the end of a normal expiration during uterine relaxation and recorded in $\mathrm{cm}$ to the nearest $0.5 \mathrm{~cm}$.

Pelvic examination was done to evaluate the station. The interval between these measurements and the delivery was within 24 hours.

Maternal weight measurement was done using weighing scale after correcting zero-error and recorded to the nearest $0.5 \mathrm{~kg}$.

Baby weight measurement: The baby's weight at delivery was taken using weighing scale after correcting for zeroerror within 12 hours of delivery.

\section{Data Analysis}

The analysis was with SPSS version 16. Descriptive statistics were calculated for continuous variables. The simple equation was obtained by equating the mean birth weight to the mean values SFH and MAG in this equation, SFH (MAG-X), and the value of $\mathrm{X}$ was determined. Linear regression model was the correlation between the estimated birth weight, SFH (MAG-X), and the birth weight.

From simple regression equation, TBPC was produced putting the intercept of 1000 and slope of 0.7 into consideration. The values of SFH (MAG-X) corresponding to $4000 \mathrm{gm}$ and $2500 \mathrm{gm}$ were also considered. In TBPC, EBW <2500gm was painted blue, while that between $2500 \mathrm{gm}$ and $3999 \mathrm{gm}$ was GREEN. $\mathrm{EBW} \geq 4000 \mathrm{gm}$ was painted. 


\section{RESULTS}

Three hundred patients were recruited (Table 1). The parity ranged from 0 to 6 while the maternal weight ranged from 50 to $95 \mathrm{~kg}$ with the mean value of $74.77 \pm 10.65 \mathrm{~kg}$. The SFH and MAG ranged from 27 to $63 \mathrm{~cm}$ and 35 to $120 \mathrm{~cm}$ while their mean values were $36.86 \pm 3.745 \mathrm{~cm}$ and $98.88 \pm 9.259 \mathrm{~cm}$ respectively. The birth weight ranged from 2300 to $4750 \mathrm{~g}$ with a mean of $3364 \pm 492.24 \mathrm{~g}$.

Table 1: The range and mean of the participants.

\begin{tabular}{|llllll|}
\hline Parameters & No. & Minimum & Maximum & Mean & $\begin{array}{l}\text { Std. } \\
\text { Deviation }\end{array}$ \\
\hline Parity & 300 & 0.0 & 6.0 & 1.421 & 1.2859 \\
\hline Mwt $(\mathrm{kg})$ & 300 & 50.0 & 95.0 & 74.774 & 10.6575 \\
\hline SFH $(\mathrm{cm})$ & 300 & 27.0 & 63.0 & 36.865 & 3.7445 \\
\hline MAG $(\mathrm{cm})$ & 300 & 35.0 & 120.0 & 98.885 & 9.2592 \\
\hline Bwt $(\mathrm{g})$ & 300 & 2300.0 & 4750.0 & 3363.50 & 492.2362 \\
\hline
\end{tabular}

Mwt=maternal weight, $\mathrm{SFH}=$ Sphysiofundal height, $\mathrm{MAG}=$ maternal abdominal girth, $\mathrm{Bwt}=$ birth weight, $\mathrm{Std}=$ standard deviation.
The mean birth weight was equated to the mean values $\mathrm{SFH}$ and MAG in this equation, SFH (MAG-X).

Therefore Mean BWT = Mean SFH $($ Mean MAG - X),

$$
3,364 \mathrm{~g}=36.865(98.885-\mathrm{X}) \mathrm{cm},
$$

$X=7.6 \mathrm{~cm}$. The value of $X$ was found to be $7.6 \mathrm{~cm}$.

To reduce overestimation, without eliminating it completely; the $\mathrm{X}$ value is taken as $7 \mathrm{~cm}$.

The new formula is therefore Birth weight $(\mathrm{g})=$ SFH (MAG - 7) cm.

Table 2 demonstrated the regression equation of the birth weight and the estimated birth weight, SFH (MAG-7). The regression of the birth weight against the estimated weight was done to obtain a simple regression equation.

$\mathrm{BW}=1000+0.7 \mathrm{SFH}(\mathrm{MAG}-7)$ gram

Table 2: Simple regression equation from mean birth weight and mean estimated birth weight, SFH (MAG - 7).

\begin{tabular}{|c|c|c|c|c|c|c|}
\hline \multicolumn{7}{|c|}{ Coefficients $^{\mathrm{a}}$} \\
\hline \multirow[t]{2}{*}{ Model } & & \multicolumn{2}{|c|}{ Unstandardized Coefficients } & $\begin{array}{l}\text { Standardized } \\
\text { Coefficients }\end{array}$ & \multirow[t]{2}{*}{$t$} & \multirow[t]{2}{*}{ Sig. } \\
\hline & & $\mathrm{B}$ & Std. Error & Beta & & \\
\hline \multirow{2}{*}{1} & (Constant) & 1000.385 & 211.941 & & 4.831 & .000 \\
\hline & formula & 0.700 & 0.062 & 0.708 & 11.160 & .000 \\
\hline
\end{tabular}

a. Dependent Variable: Birth wt

From the simple regression equation, Birth weight $=1000$ +0.7 SFH $(\mathrm{MAG}-7)$, where 1000 is the intercept, 0.7, the slope. With the actual birth weight on the y-axis and estimated birth weight on the x-axis, a birth weight predicting chart was constructed as in Figure 1.

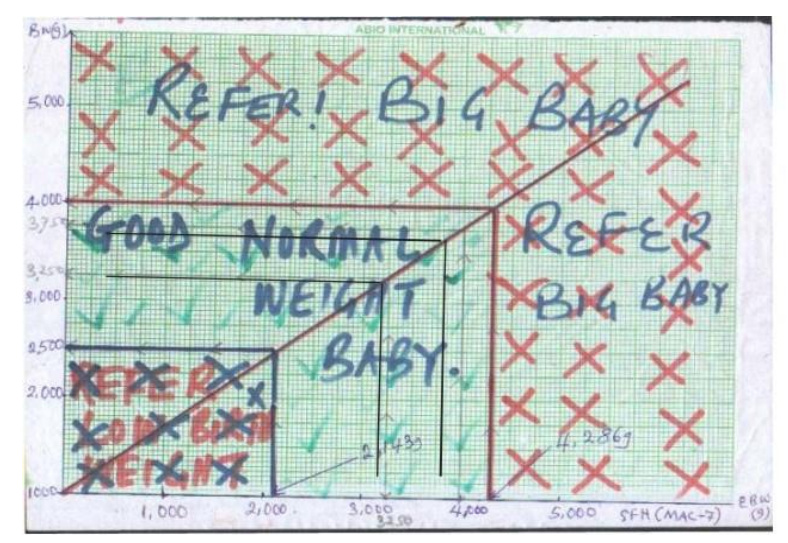

Figure 1: Tricolor Birth weight predicted chart (TBPC).
Table 3: The error margins of the different formulae.

\begin{tabular}{|lll|}
\hline Formulae & $\begin{array}{l}\text { EBW } \\
\text { (grams) }\end{array}$ & $\begin{array}{l}\text { Error margins } \\
\text { (grams). } \\
\text { EB W - Birth } \\
\text { weight }\end{array}$ \\
\hline SFH x MAG & 3649 & 285 \\
SFH(MAG - 7) & 3391 & 27 \\
Simple Regression equ. & 3374 & 10 \\
Graph & 3370 & 6 \\
\hline
\end{tabular}

EBW= estimated birth weight

Table 3 showed the mean error margins of various formulae, it demonstrated the difference between the estimated birth weight of each formulae and the birth weight,

The error margin of the four formulae, where the mean actual birth weight $=3,364 \mathrm{~g}$, mean $\mathrm{SFH}=36.9 \mathrm{~cm}$, mean MAG $=98.9 \mathrm{~cm}$. This shows that SFHXMAG has the 
highest error margin (285g) while the new formula, simple regression equation and the tricolor chart have minimal error margins of 27,10 and 6grams respectively.

\section{DISCUSSION}

Equipped with information about the weight of the fetus, the obstetrician is able to pursue sound obstetric management thus decreasing perinatal morbidity and mortality. Despite its limitations, clinical methods of assessing the fetal weight are still the simplest, cheapest and the most readily available.

This simple formula, SFH (MAG-7), is similar to that of Dare et $\mathrm{al}^{10}$ where the EBW was the product of SFH and MAG (both in $\mathrm{cm}$ ) expressed in grams, except that before the multiplication, the correction factor, 7, was subtracted from MAG. This reduces the much overestimation of birth weight by Dare's formula. Although, Dare argues that the overestimation helps local staff for earlier referral, but this overestimation is much and it raises false alarm that most of the patients referred, deliver normal size babies, therefore there is the need to reduce the false alarm. Some degree of overestimation was allowed in this new formula as 7 instead of $7.6 \mathrm{~cm}$ was used as correction factor.

There was a good correlation between the EBW, SFH (MAG-7), and the birth weight of the babies (3391g vs. $3363 \mathrm{~g}$ ), with a simple regression equation of $\mathrm{BW}$ $=1000+0.7$ SFH (MAG-7) grams. This is expressed as that addition of $1000 \mathrm{~g}$ to the product of EBW and 0.7. This gives more precise estimated birth weight than the simple formula, SFH (MAG-7), but it is more cumbersome. This is similar to the simple regression equation produced by Helmut et al. ${ }^{13}$ in Sweden (1985): BW $=1229+0.65\left(\mathrm{SFH}^{*} \mathrm{MAG}\right)$, except that the correction factor was considered in this new formula.

Because of the cumbersomeness of this regression equation, it is reduced to pictorial form to make it attractive for local health workers that may not be so good in mathematics. This TPBC was produced with $1000 \mathrm{~g}$ as the intercept and 0.7 as the slope. In its usage, the EBW, SFH (MAG-7) in $\mathrm{x}$-axis was correlated to the birth weight in the y-axis e.g. the EBW of 2,143g and 4,286g correlated with the birth weight of $2,500 \mathrm{~g}$ and $4,000 \mathrm{~g}$ respectively. Therefore the EBW $<2,143 \mathrm{~g}$ or $\geq 4,286 \mathrm{~g}$ should be referred for expert management. This chart combines both overestimation and underestimation depending on the level of the EBW. EBW equals the birth weight at the level of $3,250 \mathrm{~g}$; above this, it tends to overestimate the birth weight and below, it underestimates. This unique feature is of great advantage in that it alerts the health worker earlier enough of macrosomia, so also that of low birth weight. When the EBW $<2,143 \mathrm{~g}$ or $\geq 4,286 \mathrm{~g}$, it signifies low birth weight and macrosomia respectively. The normal EBW for delivery in the primary health centers falls between $2,143 \mathrm{~g}$ and 4,286g; any value outside this range is for referral.
The TBPC is a landmark achievement in the management of labor; it is a pictorial chart and simple to use. It has 3 zones - Blue, green and red zones. The blue and red zones represent the low birth weight and macrosomia respectively while the green zone represents the normal birth weight. Midwives at the peripheral centre should refer any woman with estimated birth weight that falls under blue and red zones as low birth weight and macrosomic babies respectively to a higher centre. The midwives should only manage those pregnancies whose expected birth weight is in the green zone. This chart is invaluable in the prediction of birth weight and referral from primary health centers. It will help in the reduction of maternal and perinatal morbidity and mortality in our health system.

\section{CONCLUSION}

New formula, SFH (MAG-7), Simple regression equation, $1000+0.7 \mathrm{SFH}$ (MAG- 7), and TBPC are for birth weight estimation. TBPC should be used in the peripheral centers by the midwives in the prediction of birth weight and referral made when necessary to a higher centre. This will reduce perinatal and maternal morbidity and mortality. Further studies are however, necessary to improve on the accuracy of this new formula and compare it with ultrasound in predicting birth weight. This is important for developing countries like ours where ultrasound and expertise are not readily available.

\section{Limitations}

It was difficult weighing patients in advanced labor. Some of the patients had much adipose tissue deposited at the anterior abdominal wall, even though they are not obese.

\section{ACKNOWLEDGEMENTS}

We hereby appreciate the effort of the residents and labour words nurses who helped in informing us when the patients come in labour.

Funding: No funding sources Conflict of interest: None declared

Ethical approval: The study was approved by the Institutional Ethics Committee

\section{REFERENCES}

1. Akinola S, Oluwafemi K, Ernest O, Niyi O, Solomon $\mathrm{O}$, Oluwagbemiga $\mathrm{O}$ Ayoola et al. Clinical Vs.Sonographic estimation of fetal Weight in South west, Nigeria. Journal of Health, Pop \& Nutr. March. 2007;25(1):14-23.

2. Onah HE, Ikeme ACC, Nkpo PO. Correlation between intrapartum $\mathrm{FH}$ and Birth weight. African Journal of Rep Health. 2002;6(2):23-9. 
3. Gerard GN., Estimation of foetal weight. A review Article last updateApril15, 2010. Available on. emedicine. Com. accessed on $15^{\text {th }}$ September, 2010.

4. Ayoola OO, Orji EO, Adetiloye VA, Nzeh DA. Accuracy of various ultra formula in predicting fetal weight in a Nigerian population Journal of Chinese Clinical medicine. 2008;3(1).

5. Aghababii S, Nahidi F. The use of Tricolour measuring tape as a predictor of birth weight. $\mathrm{J}$ med Sci. 2005;5(4):307-10.

6. Gary C , Kenneth H, Steven L. Foetal Growth disorders in William Obstetrics, 22 nd edition; McGRAW-Hill medical publishing division, 2005; $893-910$.

7. Bothner BM, Gulmezoglu AM, Holmeyr GS. SFH measurements during labour; A prospective descriptive study. African Journal of Rep. Health. 2000;4(1):48-55.

8. Gerard G, Nahum, Harold S. Ultrasonographic prediction of term birth weight. Am J Obstet Gynaecol. 2003;188(2):566-74.

9. Egwuatu VE, Osefor NJ. SFH, Abd. Circumference measurements: Foetal Age Relationship in Nigerian women. W Afr J of medicine. 1988;7(2):77-88.
10. Dare FO, Ademowore AS, Ifaturoti OO, Nganwuchi A. The value of SFH/Abd girth measurement in predicting foetal wt. International Journal of Gynaecology \& Obstetric. 1990;31(3):243-8.

11. Bhandary AA, Pinto PJ, Shetly AP. Comparative study of various methods of fetal weight estimation at term pregnancy. J Obstel Gynecol. 2004;54(4):336-9.

12. Joseph SK, Hextan YS, Kelly KL, Fung KP, Vivian C.W. Estimation of Fetal wt in utero from symphsiofundal height and Abd. Girth measurement.Aust. NZ J Obstet Gynaecol 1985;25:268-71.

13. Helmut P, Goran S. Estimation of Foetal weight by external Abdominal Measurement. Acta Obstet Gynecol Scan. 1984;62:175-9.

Cite this article as: Okolie VE, Nwosu BO, Obiechina NJA, Okechukwu ZC, Egeonu R.

Derivation of new clinical formulae and tricolor predicting chart for estimating birth weight at term. Int J Reprod Contracept Obstet Gynecol 2015;4:1048-52. 